\title{
An improved smooth-windowed wigner-ville distribution analysis for voltage variation signal
}

\author{
Mustafa Manap ${ }^{1}$, Abdul Rahim Abdullah ${ }^{2}$, Srete Nikolovski $^{3}$, Tole Sutikno ${ }^{4}$, Mohd Hatta Jopri \\ ${ }^{1,5}$ Faculty of Electrical and Electronic Engineering Technology, Universiti Teknikal Malaysia Melaka, Malaysia \\ ${ }^{2}$ Faculty of Electrical Engineering, Universiti Teknikal Malaysia Melaka, Malaysia \\ ${ }^{3}$ Power System Department, Faculty of Electrical Engineering, University of Osijek, Croatia \\ ${ }^{4}$ Deparment of Electrical Engineering, Universitas Ahmad Dahlan, Indonesia
}

\begin{abstract}
Article Info
Article history:

Received Mar 25, 2019

Revised Apr 17, 2020

Accepted Apr 25, 2020

Keywords:

Kernel parameters

Smooth-windowed wigner-ville

distribution

Voltage variation signal

ABSTRACT

This paper outlines research conducted using bilinear time-frequency distribution (TFD), a smooth-windowed wigner-ville distribution (SWWVD) used to represent time-varying signals in time-frequency representation (TFR). Good time and frequency resolutions offer superiority in SWWVD to analyze voltage variation signals that consist of variations in magnitude. The separable kernel parameters are estimated from the signal in order to get an accurate TFR. The TFR for various kernel parameters is compared by a set of performance measures. The evaluation shows that different kernel settings are required for different signal parameters. Verification of the TFD that operated at optimal kernel parameters is then conducted. SWWVD exhibits a good performance of TFR which gives high peak-to-side lobe ratio (PSLR) and signal-to-cross-terms ratio (SCR) accompanied by low main-lobe width (MLW) and absolute percentage error (APE). This proved that the technique is appropriate for voltage variation signal analysis and it essential for development in an advanced embedded system.
\end{abstract}

Copyright (C) 2020 Institute of Advanced Engineering and Science. All rights reserved.

\section{Corresponding Author:}

Mustafa Manap,

Faculty of Electrical and Electronic Engineering Technology,

Universiti Teknikal Malaysia Melaka (UTeM),

Jalan Hang Tuah Jaya, 76100 Durian Tunggal, Melaka, Malaysia

Email: mustafa@utem.edu.my

\section{INTRODUCTION}

Voltage variation comprises of voltage sag, swell and interruption and is generally characterized by its magnitude and duration. Voltage sag can be defined as the reduction of root mean square (rms) voltage between $10 \%$ and $90 \%$ of the nominal voltage $[1,2]$. The duration of voltage sag is usually a half cycle to 1 minute of time. Meanwhile, the definition of voltage swell can be described as an increase of 110 to $180 \%$ in rms of the nominal voltage for the duration of 0.5 cycles to a minute $[3,4]$. Interruption is defined as the complete loss or decreases to less than 0.1 pu of supply voltage for a period not exceeding 1 minute [5-7]. Although interruptions are more severe than voltage sag and swell, the financial losses due to voltage sag and swell are comparatively the largest $[8,9]$. This explains why the increasing concern regarding voltage variation become one of the most pressing issues that resulted in losses of up to million dollars [10]. For these reasons, the analysis of voltage variation became a vital concern to the industries which operate in a competitive business environment [11, 12].

Time-frequency distributions (TFDs) are cused to represent the signal in joint time-frequency representations (TFR) $[15,14]$. A common linear TFD is a short-time Fourier transform (STFT) $[15,16]$. This technique uses a fixed analysis window [17-19]. Its main disadvantage is the compromise between frequency and time resolution [20,21]. The bilinear TFD displays a better distribution compare to linear TFD as it offers a high resolution in both frequency and time domains [22, 23]. However, the existence of 
cross-terms make this technique difficult to interpret the true signal characteristics. In addition, in order to remove the cross-terms, all types of signals cannot use the same kernel setting [24]. As a result, it is necessary to identify the optimal and the best kernel parameter for employing the TFD.

An improvement of SWWVD analysis is presented in this paper for a voltage variation signal. These are made up of a separable kernel, with the parameters of SWWVD estimated based on the time-lag signal characteristics. Kernel parameters can include preserved auto terms in addition to the removal of cross terms. To measure the accuracy of resulting TFR, a performance verification is measured based on the MLW, PSLR, SCR and APE.

\section{THE SIGNAL MODEL}

Due to create signals for analysis, some parameters of each signal are introduced and allowed to be changed randomly such as the magnitude, frequency, starting time, and duration of the voltage variation signal [25]. The voltage variation comprises of a complex exponential signal which is expressed, as

$$
x_{v v}(t)=e^{j 2 \pi f_{0} t} \sum_{k=1}^{K} A_{k} \Pi_{k}\left(t-t_{k-1}\right)
$$

whereby the signal component sequence, $k$, signal component amplitude, $A_{k}$, fundamental frequency, $f_{0}$, of the signal, $t$ is the time, a box function, $\Pi(t)$ of the signal and the number of the signal component, $K$ [26].

For this research, the signal model parameters based on IEEE Std. 1159 (2009) and $f_{0}$ is set at $50 \mathrm{~Hz}$. The voltage variation comprises of three signal components and $K$ is set at 3 .

- Swell: A2 = 1.2, A1 = A3 = $1 ; \mathrm{t} 1=100 \mathrm{~ms}$ and $\mathrm{t} 2=140 \mathrm{~ms}$

- Sag: $\mathrm{A} 1=\mathrm{A} 3=1, \mathrm{~A} 2=0.8 ; \mathrm{t} 1=100 \mathrm{~ms}$ and $\mathrm{t} 2=140 \mathrm{~ms}$

- Interruption: $\mathrm{A} 2=0, \mathrm{~A} 1=\mathrm{A} 3=1 ; \mathrm{t} 1=100 \mathrm{~ms}$ and $\mathrm{t} 2=140 \mathrm{~ms}$

\section{THE BILINEAR TIME-FREQUENCY DISTRIBUTIONS}

The bilinear term can be expressed as [27]:

$$
P_{x}(t, f)=\int_{-\infty}^{\infty} G(t, \tau) \underset{(t)}{*} K_{x}(t, \tau) \exp (-j 2 \pi f \tau) d \tau
$$

where $G(t, \tau)$ known as the kernel of time-lag with different function for each TFD. The signal of interest, $x(t)$ of bilinear product, $K_{x}(t, \tau)$, and the $t$ with asterisk represents the signals time convolution. The bilinear product is written as:

$$
K_{x}(t, \tau)=x(t+\tau / 2) x^{*}(t-\tau / 2)
$$

\section{THE SMOOTH-WINDOWED WIGNER-VILLE DISTRIBUTION}

The SWWVD has a separable kernel and the main benefit is to reduce the effects of the cross-terms or interferences and to acquire high time-frequency resolution [28]. The separable kernel is expressed as:

$$
G(t, \tau)=H(t) w(\tau)
$$

where he time smooth $(\mathrm{H}(\mathrm{t}))$, smooth function (TS), and the lag window function $(w(\tau))$. The SWWVD function can be written as:

$$
P_{S W W V D, x}(t, f)=\int_{-\infty}^{\infty} H(t) \underset{(t)}{*} K_{x}(t, \tau) w(\tau) \exp (-2 \pi f \tau) d \tau
$$

This research use the Hamming window as the lag-window and the TS function, $H(t)$ will use raised-cosine pulse. The hamming window and the raised-cosine pulse are defined as [29]: 


$$
\begin{gathered}
w(\tau)=\left\{\begin{array}{lc}
0.54+0.64 \cos \frac{\pi \tau}{T_{g}} & -T_{g} \leq \tau \leq T_{g} \\
0 & \text { elsewhere }
\end{array}\right. \\
H(t)= \begin{cases}1+\cos \left(\pi t / T_{s m}\right) & 0 \leq t \leq T_{s m} \\
0 & \text { elsewhere }\end{cases}
\end{gathered}
$$

The $w(\tau)$ has a cut-off lag at $\tau=T_{g}$ and resulting the Doppler representation in $H(t)$, based on the Fourier transform accordingly to time is:

$$
\begin{aligned}
h(v)= & \frac{\sin \left(\pi v T_{s m}\right)}{\pi v T_{s m}}+\frac{1}{2} \frac{\sin \left(\pi\left(v-1 / 2 T_{s m}\right)\right)}{\pi\left(v-1 / 2 T_{s m}\right)} \\
& +\frac{1}{2} \frac{\sin \left(\pi\left(v+1 / 2 T_{s m}\right)\right)}{\pi\left(v+1 / 2 T_{s m}\right)}
\end{aligned}
$$

The cut-off Doppler frequency for low-pass filter in the Doppler domain is:

$$
v_{c}=3 / 2 T_{s m}
$$

\section{KERNEL ANALYSIS IN TIME-LAG REPRESENTATION}

The signal product of bilinear product is represented in the time-lag domain. The product of bilinear comprises of auto-terms and cross-terms. The bilinear product written as:

$$
K_{x}(t, \tau)=K_{x, \text { auto }}(t, \tau)+K_{x, \text { cross }}(t, \tau)
$$

The auto-terms are centered at $\tau=0$ and concentrated alongside the time axis of the time-lag representation. Meanwhile, the cross-terms are positioned away from the axis. It is important to choose appropriate kernel parameters which will retain the auto-terms while at the same time suppressing the cross-terms. The separable kernel of SWWVD consist of the lag window and TS function as defined in (6) and (7), respectively. The Doppler-frequency existing in cross-terms and removed by the TS function. Furthermore, the lag window will suppresses any cross-terms that away of the lag axis origin. The time-lag representation is depends on the signal characteristics, take note that no single kernel setting that can be utilized for all signals.

\subsection{The bilinear product of voltage variation signal}

Equation (1) expressed the voltage variation signal and it has a variation of the root mean square (RMS) value of the nominal voltage [8]. The auto-terms and cross-terms of this signal are distinguished by substituting the (1) into (3), respectively and expressed as:

$$
\begin{aligned}
& K_{\text {auto,vv }}(t, \tau)=\sum_{k=1}^{3} A_{k}^{2} e^{j 2 \pi f_{0} \tau} K_{\Pi_{k, k}}(t, \tau) \\
& K_{\text {cross, } v v}(t, \tau)=\sum_{\substack{k=1 \\
k \neq l}}^{3} \sum_{l=1}^{3} A_{k} A_{l} e^{j 2 \pi f_{0} \tau} K_{\Pi_{k, l}}(t, \tau)
\end{aligned}
$$

whereby the signal components sequence represented as $k$ and $l . A_{k}$ and $A_{l}$ are the amplitude of the signal components, $f_{0}$ is the signal fundamental frequency. The box function, $\Pi(t)$ is a bilinear product and can be written as:

$$
K_{\Pi_{k, l}}(t, \tau)=\Pi_{k}\left(t+\tau / 2-t_{k}\right) \Pi_{l}\left(t-\tau / 2-t_{l}\right)
$$


From (11) and (12), it is detected that the cross-terms are located elsewhere whereas the auto-terms centered at $\tau=0$ and alongside the time axis and are. This is shown in Figure 1.

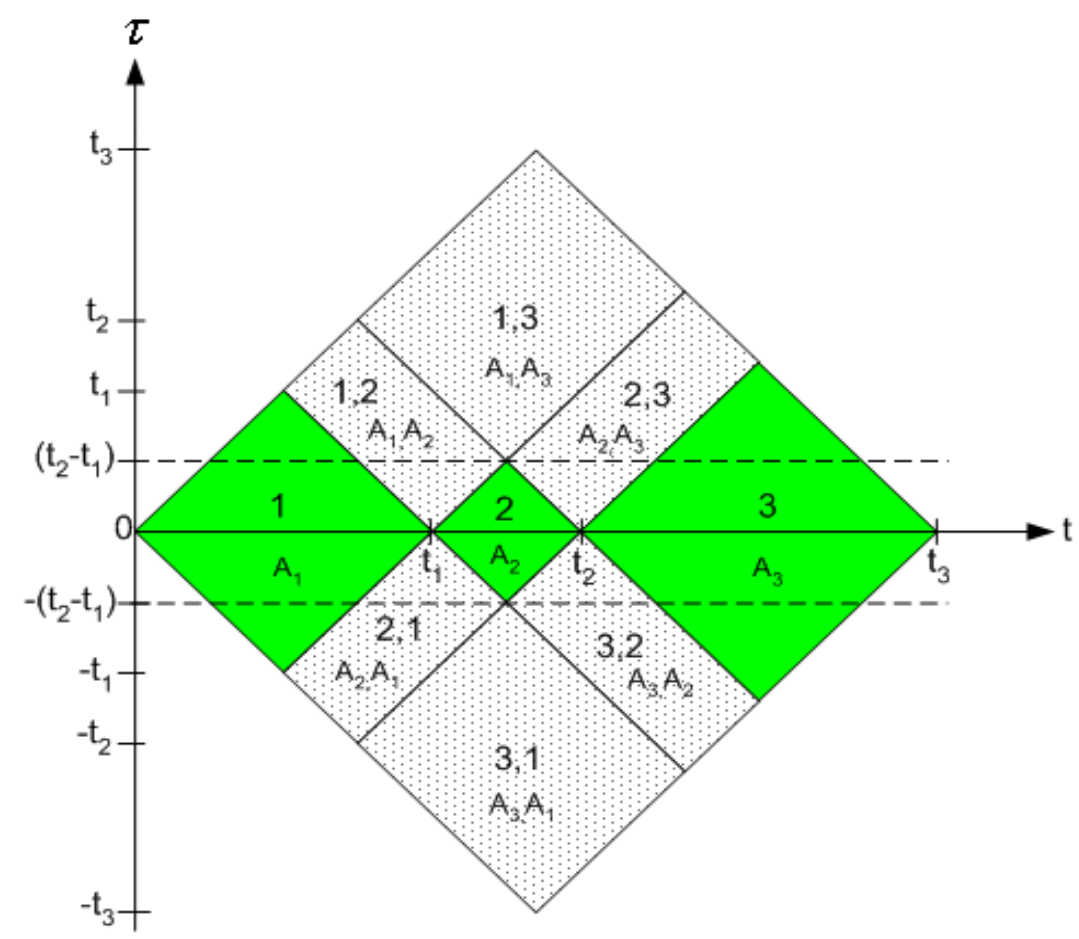

Figure 1. The voltage variation signal bilinear product (densely dotted region are cross-terms whereas the auto-terms are green highlighted)

For example, auto-term at $k=1$ and $l=1$, the bilinear product is written as:

$$
K_{\text {auto,vv }}\left(t-t_{1} / 2, \tau\right)=A_{1}^{2} e^{j 2 \pi f_{1} \tau} K_{\Pi_{1,1}}\left(t-t_{1} / 2, \tau\right)
$$

This auto-term located at of the lag axis origin $t=t_{1} / 2$. It comprises a single lag-frequency of the signal component at the condition of $f=f_{0}$. Correspondingly, for the auto-term at $l=2$ and $k=2$. It can be expressed as:

$$
K_{\text {auto, }, v}\left(t-\left(t_{1}+t_{2}\right) / 2, \tau\right)=A_{2}^{2} e^{j 2 \pi f_{0} \tau} K_{\Pi_{2,2}}\left(t-\left(t_{1}+t_{2}\right) / 2, \tau\right)
$$

When $\mathrm{k}=1$ and $\mathrm{l}=2$ of the cross-terms, at $\tau=t_{2} / 2$ and $t=\left(t_{2}+2 t_{1}\right) / 4$. The interaction between first and second signal components known as the cross-term. Furthermore, only a component of a single lag-frequency exist at $f=f_{0}$. It can be written as:

$$
\begin{aligned}
& K_{\text {cross }, v v}\left(t-\left(t_{2}+2 t_{1}\right) / 4, \tau-t_{2} / 2\right)=A_{1} A_{2} e^{j 2 \pi f_{0} \tau} \\
& K_{\Pi_{1,2}}\left(t-\left(t_{2}+2 t_{1}\right) / 4, \tau-t_{2} / 2\right)
\end{aligned}
$$

Due to supress the cross-terms and to preserve the auto-terms, the lag-window cover all the auto-terms and remove the cross-terms as much as it can. The width of lag-window, $T_{g}$, can be defined as:

$$
T_{g} \leq\left|t_{2}-t_{1}\right|
$$

Figure 2 shows the effect of utilizing the limit is that the cross-terms at $l=2, k=1$, and $l=3, k=2$ are preserved as they are in line to the auto-terms. By using smaller $T_{g}$, the remaining cross-terms can be 
removed. However this condition will reduce the auto-terms concentration and the frequency resolution. The impact of this setting will be explained in the results chapter.

The Doppler-frequency does not exist in the cross-terms, thus the cross-terms suppression can be obtained using the TS function. The TFD that used an impulse function and lag window in TS function known as windowed Wigner-Ville distribution (WWVD). The WWVD can be written as:

$$
\rho_{z, w w v d}(t, f)=\int_{-\infty}^{\infty} K_{z}(t, \tau) w(\tau) e^{-j 2 \pi f \tau} d \tau
$$

whereby $w(\tau)$ is the lag window.

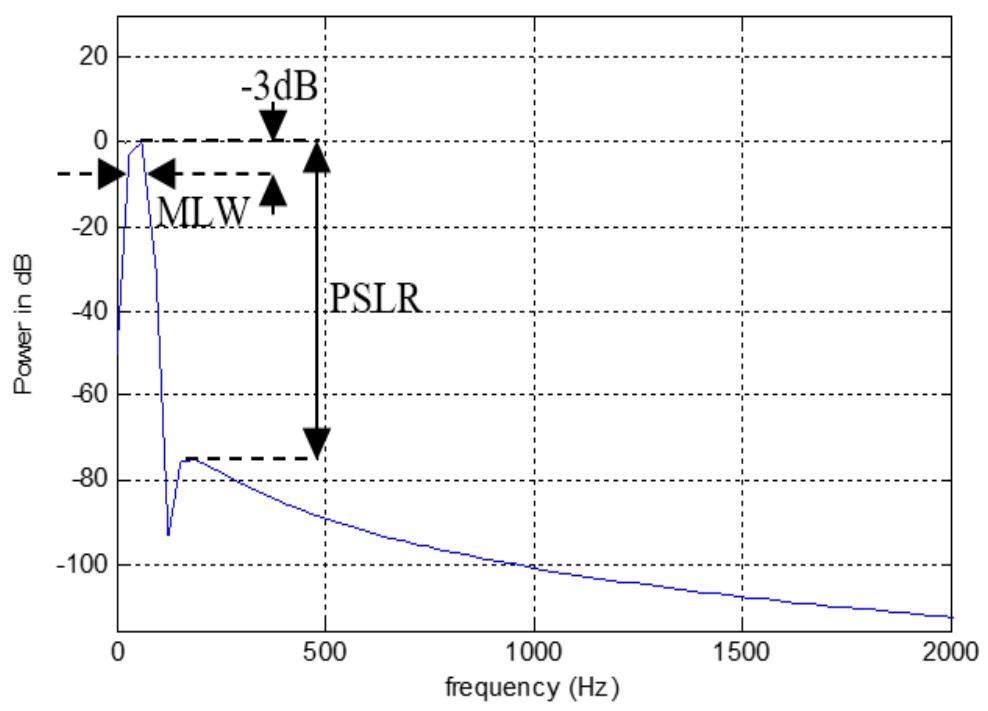

Figure 2. Performance measurements used of the analysis

\subsection{Kernel parameters}

The kernel parameters limitation $\left(T_{s m, m i n}\right)$ are defined in equation (18) and tabulates in Table 1. The smallest of lag-window width, $T_{g, \min }$, and the parameter of TS function, $T_{s m, \min }$, are defined in equation (6) and (7), respectively. Thus, the satisfactory suppression of cross-terms with minimal bias for auto-terms is obtained using these parameters. This setting also reduce the computational complexity and amount of memory required for the analysis.

Table 1. The kernel parameters limit utilizing SWWVD

\begin{tabular}{ccc}
\hline Signal & $T_{g, \min }(\mathrm{ms})$ & $T_{s m, \min }(\mathrm{ms})$ \\
\hline Sag & 10 & 0 \\
Interruption & 10 & 0 \\
Swell & 10 & 0 \\
\hline
\end{tabular}

\section{PERFORMANCE MEASUREMENTS OF KERNEL PARAMETERS}

A verification of SWWVD is obtained by apply measurement techniques such as signal-to-crossterms ratio (SCR), main-lobe width (MLW), peak-to-side lobe ratio (PSLR), and absolute percentage error (APE). These techniques are used to calculate the accuracy, resolution, minimization of interference, and concentration of the TFR [29]. As shown in Figure 2, due to calculate the MLW and PSLR, the power spectrum is required and it can be acquired from the TFR frequency marginal. Furthermore, the width of MLW is $3 \mathrm{~dB}$ and it is below the power spectrum peak. Meanwhile, the power ration between the peak and the highest side-lobe known as PSLR. To obtain a good resolution of frequency, the MLW must be low whereas to resolve various signal size, the PSLR must be high as possible. 
The ratio of the signal to the cross-terms power known as SCR and the unit is $\mathrm{dB}$. Note that, the higher value SCR means the higher the cross-terms suppression of the TFR. The SCR is expressed as [30]:

$$
\mathrm{SCR}=10 \log \left(\frac{\text { signal power }}{\text { cross }- \text { terms power }}\right)
$$

Besides APE is also used to measure the accuracy of the TFR. The APE is written as:

$$
\mathrm{APE}=\frac{x_{i}-x_{m}}{x_{i}} \times 100 \%
$$

whereby $x_{m}$ is a measured value and $x_{i}$ is the actual value. The lower value of APE designates the higher of measurement accuracy. Note that, to get optimum TFD kernel, it is compulsory to have high PSLR and SCR whereas the MLW must be lowest as possible.

\section{RESULTS AND DISCUSSION}

\subsection{Voltage variation signal analysis using SWWVD}

The examples of the voltage variation signal and the TFRs utilizing SWWVD at optimal kernel are shown in Figure 3 to 5. The graph shows the signal in the time domain whereas the plot of contour shows its TFR. Figure 3 shows an interruption signal in the time domain and its TFR at $T_{\mathrm{g}}=10 \mathrm{~ms}$ and $\mathrm{T}_{\mathrm{sm}}=0 \mathrm{~ms}$. The magnitude of the signal goes to zero with duration of $40 \mathrm{~ms}$ at $100 \mathrm{~ms}$. The contour plot shows that the power of the signal decreases to zero between 100 and $140 \mathrm{~ms}$. During convolution between the signal and kernel, the TFDs shifts induce some delays to the TFRs in the time domain compared to the input signals.
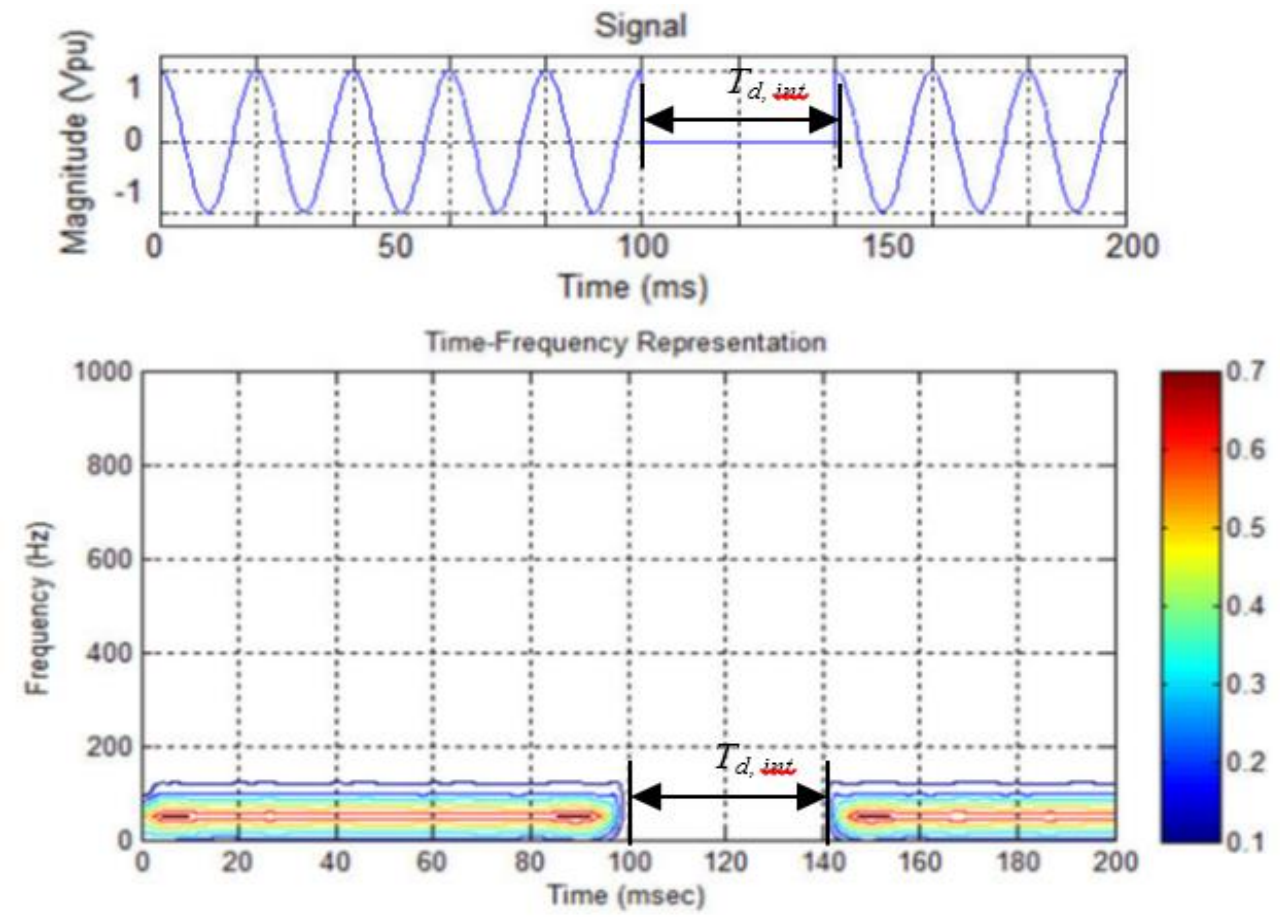

Figure 3. The TFR of interruption signal at $\mathrm{T}_{\mathrm{g}}=10 \mathrm{~ms}$ and $\mathrm{T}_{\mathrm{sm}}=0 \mathrm{~ms}$ utilizing $\mathrm{SWWVD}$

Figure 4 shows the wwell signal in the time domain and its TFR at $T_{g}=10 \mathrm{~ms}$ and $T_{\mathrm{sm}}=0 \mathrm{~ms}$ utilizing SWWVD. The signal magnitude increase from the normal voltage (1.0 pu) to $1.2 \mathrm{pu}$ starting at 100 $\mathrm{ms}$ for a duration of $40 \mathrm{~ms}$. The contour plot shows that, the power of the signal increases between 100 and $140 \mathrm{~ms}$. Figure 5 shows a sag signal in the time domain and its TFR at $\mathrm{T}_{\mathrm{g}}=10 \mathrm{~ms}$ and $\mathrm{T}_{\mathrm{sm}}=0 \mathrm{~ms}$. The magnitude of the signal momentarily decreases with duration of $40 \mathrm{~ms}$ from 1.0 to $0.8 \mathrm{pu}$ at $100 \mathrm{~ms}$. The contour plot shows that the power of the signal decreases between 100 and $140 \mathrm{~ms}$. 

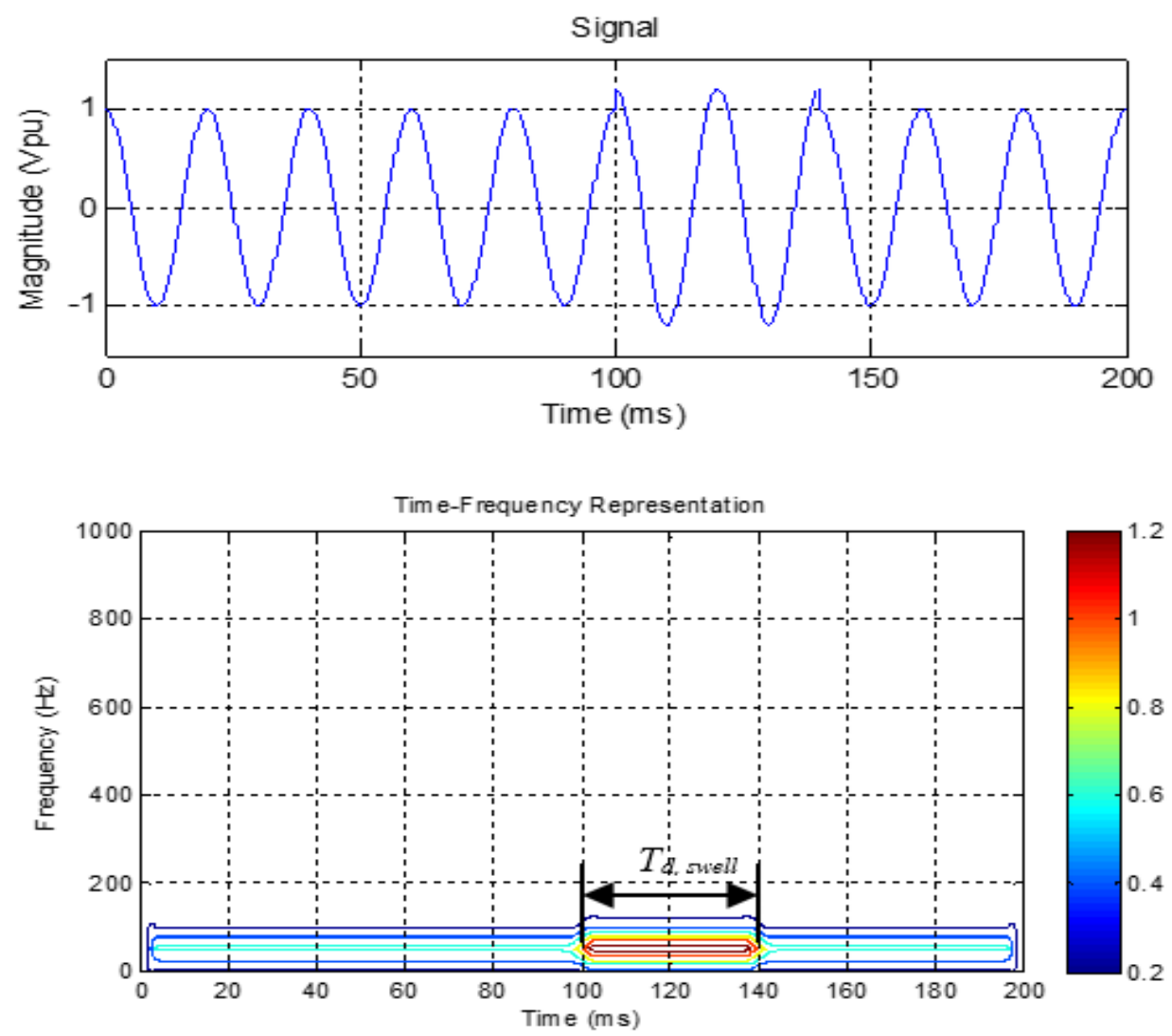

Figure 4. The TFR of swell signal at $\mathrm{T}_{\mathrm{g}}=10 \mathrm{~ms}$ and $\mathrm{T}_{\mathrm{sm}}=0 \mathrm{~ms}$ utilizing $\mathrm{SWWVD}$
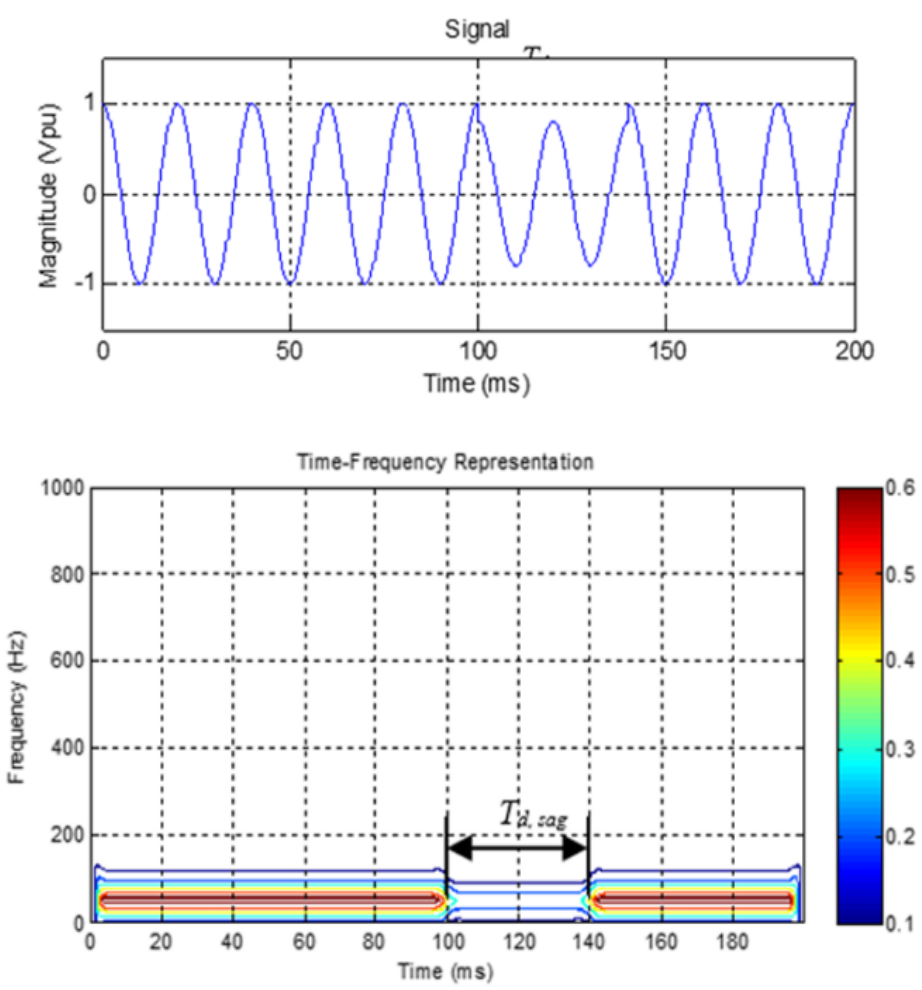

Figure 5. The sag signal TFR at $\mathrm{T}_{\mathrm{g}}=10 \mathrm{~ms}$ and $\mathrm{T}_{\mathrm{sm}}=0 \mathrm{~ms}$ utilizing SWWVD 


\subsection{Performance evaluation of smooth-windowed wigner-ville distribution}

Table 2 tabulates the performance evaluation of SWWVD with various kernel parameters of voltage variation signals. The shaded region in the table shows the parameters that provide an optimal TFR for all signals. As tabulated in Table 2, $\mathrm{Tg}=10 \mathrm{~ms}$ and $\mathrm{Tsm}=0 \mathrm{~ms}$ are the optimal kernel parameters for voltage variation signal. To evaluate the performance response of the kernel parameters, the evaluation has been done at optimal $\mathrm{T}_{\mathrm{sm}}$ with various $\mathrm{T}_{\mathrm{g}}$ and shown in Figure 6, whereas Figure 7 shows the optimal $\mathrm{T}_{\mathrm{g}}$ with various $\mathrm{T}_{\mathrm{sm}}$.

Figure 6 presents that the MLW is smallest value when optimal $T_{s m}$ and $T_{g}$ is set high. This condition provides higher TFR frequency resolution. Yet, resulting a decreases of the cross-terms suppression and the SCR value is small due to high $T_{g}$ whereas additional adjacent cross-terms exist in the bilinear product. Noted that, the lower APE provides high accuracy of the measurement. The $f_{0}$ is set at $50 \mathrm{~Hz}$ and due to include the minimum of one-cycle fundamental signal, the minimum $T_{g}$ must be set at $10 \mathrm{~ms}$.

Table 2. Table styles

\begin{tabular}{|c|c|c|c|c|}
\hline \multirow[b]{2}{*}{ Kernel Parameters } & \multirow[b]{2}{*}{ Performance measurements } & \multicolumn{3}{|c|}{ Voltage variation signal } \\
\hline & & Swell & Sag & Interruption \\
\hline$T_{g}=10 \mathrm{~ms}$ & MLW (Hz) & 25 & 25 & 25 \\
\hline \multirow[t]{3}{*}{$T_{s m}=0 \mathrm{~ms}$} & PSLR (dB) & 615.53 & 615.53 & 615.53 \\
\hline & $\mathrm{SCR}(\mathrm{dB})$ & 15.641 & 17.799 & 55.446 \\
\hline & $\operatorname{APE}(\%)$ & 0.2083 & 0.625 & 0.625 \\
\hline \multirow{4}{*}{$\begin{array}{l}T_{g}=40 \mathrm{~ms} \\
T_{s m}=0 \mathrm{~ms}\end{array}$} & MLW (Hz) & 6.25 & 6.25 & 6.25 \\
\hline & PSLR (dB) & 615.642 & 615.642 & 615.642 \\
\hline & $\mathrm{SCR}(\mathrm{dB})$ & 8.9462 & 11.216 & 48.903 \\
\hline & APE (\%) & 1.4583 & 1.875 & 1.0417 \\
\hline \multirow{4}{*}{$\begin{array}{l}T_{g}=10 \mathrm{~ms} \\
T_{s m}=1.578 \mathrm{~ms}\end{array}$} & MLW (Hz) & 25 & 25 & 25 \\
\hline & PSLR (dB) & 218.09 & 216.68 & 198.78 \\
\hline & $\operatorname{SCR}(\mathrm{dB})$ & 13.491 & 15.038 & 35.107 \\
\hline & $\operatorname{APE}(\%)$ & 3.125 & 12.708 & 100 \\
\hline \multirow{4}{*}{$\begin{array}{l}T_{g}=15 \mathrm{~ms} \\
T_{s m}=1.578 \mathrm{~ms}\end{array}$} & MLW (Hz) & 13.333 & 13.333130 .68 & 13.333 \\
\hline & PSLR (dB) & 130.99 & 13.297 & 127.89 \\
\hline & $\mathrm{SCR}(\mathrm{dB})$ & 11.751 & 117.08 & 33.514 \\
\hline & $\operatorname{APE}(\%)$ & 69.791 & & 100 \\
\hline \multirow{4}{*}{$\begin{array}{l}T_{g}=20 \mathrm{~ms} \\
T_{s m}=6.67 \mathrm{~ms}\end{array}$} & MLW (Hz) & 12.5 & 12.5 & 12.5 \\
\hline & PSLR (dB) & 229.98 & 228.53 & 210.04 \\
\hline & $\mathrm{SCR}(\mathrm{dB})$ & 9.8581 & 11.485 & 31.371 \\
\hline & $\operatorname{APE}(\%)$ & 14.583 & 29.375 & 100 \\
\hline \multirow{4}{*}{$\begin{array}{l}T_{g}=40 \mathrm{~ms} \\
T_{s m}=6.67 \mathrm{~ms}\end{array}$} & MLW (Hz) & 6.25 & 6.25 & 6.25 \\
\hline & PSLR (dB) & 120.03 & 100.92 & 81.315 \\
\hline & $\mathrm{SCR}(\mathrm{dB})$ & 6.7221 & 8.4121 & 28.701 \\
\hline & $\operatorname{APE}(\%)$ & 20.416 & 35.417 & 100 \\
\hline \multirow{4}{*}{$\begin{array}{l}T_{g}=20 \mathrm{~ms} \\
T_{s m}=7.5 \mathrm{~ms}\end{array}$} & MLW (Hz) & 12.5 & 12.5 & 12.5 \\
\hline & PSLR (dB) & 229.97 & 228.53 & 209.88 \\
\hline & $\mathrm{SCR}(\mathrm{dB})$ & 9.8073 & 11.439 & 31.289 \\
\hline & APE $(\%)$ & 16.666 & 31.667 & 100 \\
\hline \multirow{4}{*}{$\begin{array}{l}T_{g}=40 \mathrm{~ms} \\
T_{s m}=7.5 \mathrm{~ms}\end{array}$} & MLW (Hz) & 6.25 & 6.25 & 6.25 \\
\hline & PSLR (dB) & 122.91 & 102.56 & 111.22 \\
\hline & $\mathrm{SCR}(\mathrm{dB})$ & 6.6568 & 8.3551 & 28.600 \\
\hline & APE (\%) & 21.458 & 36.667 & 100 \\
\hline
\end{tabular}

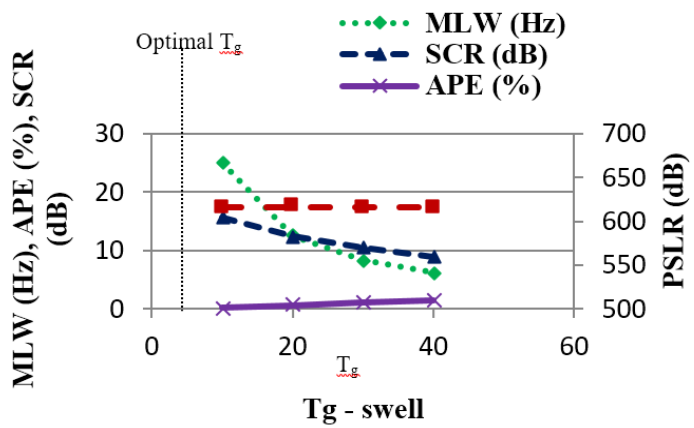

Figure 6. The TFR performance with various kernel parameters for the swell signal when APE, MLW, SCR, and PSLR optimal $\mathrm{T}_{\mathrm{sm}}$ with various $\mathrm{T}_{\mathrm{g}}$ utilizing $\mathrm{SWWVD}$ 
Figure 7 shows that the SCR and MLW are constant when the optimal $T_{g}$ and $T_{s m}$ is set higher than the optimal value. It designates that the frequency resolution and cross-terms suppress remain unchanged when $T_{s m}$ is set higher than its optimal value. However, the higher APE shows that the TFR time resolution is low. As presents in Table 2, at $T_{g}=10 \mathrm{~ms}$ and $T_{s m}=0 \mathrm{~ms}$ are the optimal kernel parameters. Furthermore, there is no improvement in the cross-terms suppression even though used the TS function as the zero Doppler frequency exist in all cross-terms. Besides, the time resolution is reduce when higher $T_{s m}$ is set. Therefore, the SCR is low and APE is high when the $T_{s m}$ is set higher from its optimal value.

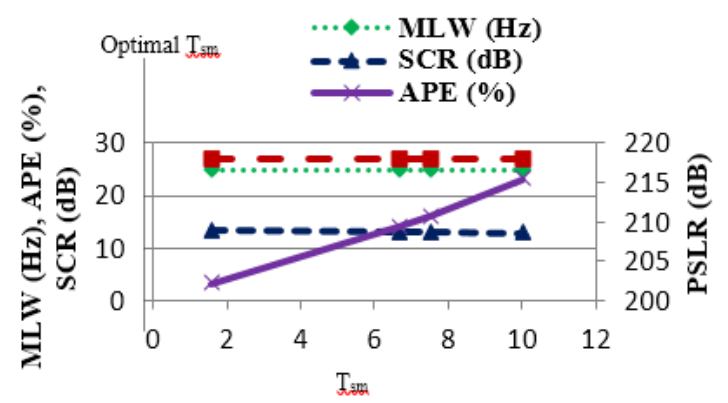

Figure 7. The TFR performance with various kernel parameters for the swell signal when APE, MLW, SCR, and PSLR optimal $\mathrm{T}_{\mathrm{g}}$ with various $\mathrm{T}_{\mathrm{sm}}$ utilizing $\mathrm{SWWVD}$

\section{CONCLUSION}

The SWWVD provides good resolution in time and frequency. The main objective to have optimal kernel is to suppress cross-terms and to preserve auto-terms of the bilinear product.In order to verify the optimal kernel, verification of performance measurement such as PSLR, SCR, MLW, and APE are performed. The optimal kernel parameters must have high PSLR and SCR, while the MLW and APE must low. From this research, it is noted that the optimal kernel for voltage variation signal, the optimal kernel are $T_{g}=10 \mathrm{~ms}$ and $T_{s m}=0 \mathrm{~ms}$.

\section{ACKNOWLEDGMENT}

The authors would like to thank the Center for Robotics and Industrial Automation of Excellence (CeRIA), Faculty of Electrical \& Electronic Engineering Technology of Universiti Teknikal Malaysia Melaka (UTeM) and ADSP Lab for this research. Their support is gratefully acknowledged.

\section{REFERENCES}

[1] M. H. Jopri, A. R. Abdullah, T. Sutikno, M. Manap, M. R. Ab. Ghani, and M. R. Yusoff, "A critical review of time-frequency distribution analysis for detection and classification of harmonic signal in power distribution system," Int. J. Electr. Comput. Eng., vol. 8, no. 6, pp. 4603-4618, 2018, doi: 10.11591/ijece.v8i6.pp.4603-4618.

[2] N. H. T. Huda, A. R. Abdullah, and M. H. Jopri, "Power quality signals detection using S-transform," Proc. 2013 IEEE 7th Int. Power Eng. Optim. Conf. PEOCO 2013, pp. 552-557, 2013, doi: 10.1109/PEOCO.2013.6564609.

[3] W. Tee, M. R. Yusoff, A. R. Abdullah, M. H. Jopri, N. S. N. Anwar, and H. Musa, "Spectrogram based window selection for the detection of voltage variation," Int. J. Integr. Eng., vol. 11, no. 3, pp. 240-247, 2019, doi: 10.30880/ijie.2019.11.03.025.

[4] A. Rahim Abdullah, N. H. T. H. Ahmad, N. a. Abidullah, N. H. Shamsudin, and M. H. Jopri, "Performance Evaluation of Real Power Quality Disturbances Analysis Using S-Transform," Appl. Mech. Mater., vol. 752-753, pp. 1343-1348, 2015, doi: 10.4028/www.scientific.net/AMM.752-753.1343.

[5] M. B. Latran and A. Teke, "A novel wavelet transform based voltage sag/swell detection algorithm," Int. J. Electr. Power Energy Syst., vol. 71, pp. 131-139, Oct. 2015, doi: 10.1016/j.ijepes.2015.02.040.

[6] N. A. Abidullah, A. R. Abdullah, N. H. Shamsudin, N. H. T. H. Ahmad, and M. H. Jopri, "Real-time power quality signals monitoring system," Proceeding - 2013 IEEE Student Conf. Res. Dev. SCOReD 2013, pp. 433-438, 2013, doi: 10.1109/SCOReD.2013.7002626.

[7] a. R. Abdullah, N. a. Abidullah, N. H. Shamsudin, N. H. H. Ahmad, and M. H. Jopri, "Power Quality Signals Classification System Using Time-Frequency Distribution," Appl. Mech. Mater., vol. 494-495, pp. 1889-1894, 2014, doi: 10.4028/www.scientific.net/AMM.494-495.1889. 
[8] D. Committee, I. Power, and E. Society, IEEE Std 1159 $9^{T M}-2009$, IEEE Recommended Practice for Monitoring Electric Power Quality, 2009.

[9] N. A. Abidullah, A. R. Abdullah, A. Zuri Sha'ameri, N. H. Shamsudin, N. H. H. Ahmad, and M. H. Jopri, "Real-time power quality disturbances detection and classification system," World Appl. Sci. J., vol. 32, no. 8, pp. 1637-1651, 2014, doi: 10.5829/idosi.wasj.2014.32.08.534.

[10] A. R. Abdullah, N. Abidullah, and M. H. Jopri, "Analysis of Power Quality Disturbances Using Spectrogram and S-transform," Int. Rev. Electr. Eng., vol. 3, no. 3, pp. 611-619, 2014.

[11] P. Thakur, A. K. Singh, and R. C. Bansal, "Novel way for classification and type detection of voltage sag," IET Gener. Transm. Distrib., vol. 7, no. 4, pp. 398-404, 2013, doi: 10.1049/iet-gtd.2012.0435.

[12] M. Manap, M. H. Jopri, A. R. Abdullah, R. Karim, and M. R. Y. A. H. Azahar, "A verification of periodogram technique for harmonic source diagnostic analytic by using logistic regression," vol. 17, no. 1, pp. 497-507, 2019, doi: 10.12928/TELKOMNIKA.v17i1.10390.

[13] P. Thakur and A. K. Singh, "Signal processing and AI based diagnosis of power quality disturbances: A review," in 2015 International Conference on Energy Economics and Environment (ICEEE), 2015, pp. 1-6, doi: 10.1109/EnergyEconomics.2015.7235071.

[14] M. H. Jopri, A. R. Abdullah, M. Manap, T. Sutikno, and M. R. A. Ghani, "An identification of multiple harmonic sources in a distribution system by using spectrogram," Bull. Electr. Eng. Informatics, vol. 7, no. 2, pp. 244-256, 2018, doi: 10.11591/eei.v7i2.1188.

[15] M. H. Jopri, A. R. Abdullah, N. M. Kassim, M. Manap, N. A. Ngatiman, and M. R. Yusoff, "Localization of Multiple Harmonic Sources for Inverter Loads Utilizing Periodogram,” J. Teknol., vol. 8, no. 2, pp. 87-91, 2016.

[16] M. H. Jopri, A. R. Abdullah, M. Manap, M. R. Yusoff, and T. Sutikno, "A fast localization of multiple harmonic sources for rectifier loads by utilizing periodogram," TELKOMNIKA Telecommunication Comput. Electron. Control., vol. 15, no. 1, 2017, doi: 10.12928/TELKOMNIKA.v15i1.3120.

[17] M. Manap, A. R. Abdullah, N. Z. Saharuddin, N. A. Abidullah, N. S. Ahmad, and M. H. Jopri, "Performance Comparison of VSI Switches Faults Analysis Using STFT and S Transform," Appl. Mech. Mater., vol. 785, pp. 210-214, 2015, doi: 10.4028/www.scientific.net/amm.785.210.

[18] M. Jopri, A. Abdullah, T. Sutikno, and M. Manap, "A Utilisation of Improved Gabor Transform for Harmonic Signals Detection and Classification Analysis," Int. J., vol. 7, no. 1, pp. 21-28, 2017, doi: 10.11591/ijece.v7i1.pp21-28.

[19] M. H. Jopri, N. A. Abidullah, G. Z. Peng, and A. R. Abdullah, "A new two points method for identify dominant harmonic disturbance using frequency and phase spectrogram," Int. Rev. Electr. Eng., vol. 9, no. 2, pp. 453-459, 2014.

[20] A. Amirou, Z. Zidelmal, and D. Ould-Abdeslam, "Stockwell-transform for electrical defaults localization," Proc. 2015 IEEE Int. Renew. Sustain. Energy Conf. IRSEC 2015, pp. 1-6, 2016, doi: 10.1109/IRSEC.2015.7454937.

[21] M. H. Jopri, A. R. Abdullah, M. Manap, M. F. Habban, and T. Sutikno, "An Accurate Classification Method of Harmonic Signals in Power Distribution System by Utilising S-Transform," TELKOMNIKA Telecommunication Comput. Electron. Control, vol. 15, no. 1, pp. 12-20, 2017, doi: 10.12928/TELKOMNIKA.V15I1.3119.

[22] J. L. Tan and A. Z. Bin Sha'Ameri, "Adaptive optimal kernel smooth-windowed wigner-ville distribution for digital communication signal," EURASIP J. Adv. Signal Process., vol. 2008, 2008, doi: 10.1155/2008/408341.

[23] M. F. B. Habban, M. Manap, A. R. Abdullah, M. H. Jopri, and T. Sutikno, "An evaluation of linear time frequency distribution analysis for VSI switch faults identification," Int. J. Power Electron. Drive Syst., vol. 8, no. 1, pp. 1-9, 2017, doi: 10.11591/ijpeds.v8i1.pp1-9.

[24] J. L. Tan and A. Z. Bin Sha'ameri, "Signal analysis and classification of digital communication signals using adaptive smooth- windowed wigner-ville distribution," Proc. IEEE 2008 6th Natl. Conf. Telecommun. Technol. IEEE 2008 2nd Malaysia Conf. Photonics, NCTT-MCP 2008, pp. 260-266, 2008, doi: 10.1109/NCTT.2008.4814284.

[25] N. H. H. A. A. R. Abdullah, N. A. Abidullah, N. H. Shamsudin and and M. H. Jopri, "Performance Verification of Power Quality Signals Classification System," Appl. Mech. Mater., vol. 753, pp. 1158-1163, 2015, doi: 10.4028/www.scientific.net/AMM.752-753.1158.

[26] M. H. Jopri, A. R. Abdullah, M. Manap, M. R. Yusoff, T. Sutikno, and M. F. Habban, "An improved detection and classification technique of harmonic signals in power distribution by utilizing spectrogram," Int. J. Electr. Comput. Eng., vol. 7, no. 1, pp. 12-20, 2017, doi: 10.11591/ijece.v7i1.pp12-20.

[27] F. A. Franz Hlawatsch, Ed., Time-Frequency Analysis. ohn Wiley \& Sons, Inc, 2013.

[28] D. Boutana, B. Barkat, and F. Marir, "A proposed High-Resolution Time-Frequency Distribution for the Analysis of Multicomponent and Speech Signals," World Acad. Sci. Eng. Technol., vol. 1, no. 2, pp. 100-103, 2005.

[29] J. L. Tan and A. Z. Bin Sha'ameri, "Adaptive smooth-windowed wigner-ville distribution for digital communication signal," Proc. IEEE 2008 6th Natl. Conf. Telecommun. Technol. IEEE 2008 2nd Malaysia Conf. Photonics, NCTT-MCP 2008, pp. 254-259, 2008, doi: 10.1109/NCTT.2008.4814283.

[30] A. R. Abdullah and A. Z. Sha'Ameri, "Power quality analysis using bilinear time-frequency distributions," EURASIP J. Adv. Signal Process., vol. 2010, 2010, doi: 10.1155/2010/837360. 